Dr. Nicola MacLeod

Faculty of Business

University of Greenwich

Maritime Greenwich campus

Park Row, Greenwich

London SE10 9LS

England

United Kingdom

Tel: +44 (0) 2083319316

Email: n.e.macleod@gre.ac.uk 


\title{
Self-guided trails - a route to more responsible tourism?
}

\begin{abstract}
In recent years, the tourism industry has faced its critics by turning its attention to the development of more responsible tourism. This is a form of tourism that is mindful of the diverse needs of host communities, local business and the visitor. This article investigates the development of more responsible tourism from the perspective of a popular tourist product - the self-guided trail or route. The trail or route provides a themed and interpreted journey through the urban or rural landscape, creating links between sites, attractions and other tourism businesses and providing information and storytelling along the way. These products have a global appeal and are becoming more prolific. Through reviewing the literature on trails the paper analyses their key characteristics and the rationales of developers and concludes that trails have the potential to contribute to more responsible tourism development. The paper goes on to propose a series of planning principles which are derived from the literature and examples of good practice therein which may assist trail developers in creating more responsible tourism routes and trails. The discussion concludes with a case study of a project in Cornwall in the south west of the UK, where responsible planning has underpinned recent trail development.
\end{abstract}

Key words

Responsible tourism; self-guided trails; routes; trail planning; tourism development; planning principles 


\section{Introduction}

Self-guided trails have been a prolific and popular tourism product since the early 1980s and yet have received relatively scant attention in the tourism management literature (Timothy \& Boyd, 2015; MacLeod \& Hayes, 2013; Prideaux \& Carson, 2003). This paper reviews the existing research on the self-guided trail and suggests that although trails have been predominantly marketing-led in the past, it is clear that they also have an important role to play in the development of more responsible tourism. Using a review of the key literature and examples of good practice in existing trails, the paper proposes a series of planning principles that might underpin the future development of self-guided trails, contributing to the well-being of environments, communities and businesses.

Responsible tourism, according to the Cape Town Declaration on Responsible Tourism (2002) is concerned with creating “.... better places for people to live in, and better places to visit” (Responsible Tourism Partnership, 2002). Responsible tourism was thus defined as a three-tiered approach: firstly, tourism development should improve the host communities’ lives, secondly, it should create better business opportunities, and thirdly, it should provide better tourist experiences (Spenceley, 2008; Frey \& George, 2010). The idea that all stakeholders within the tourism system should take responsibility for their actions has been in circulation since the 1980s and Goodwin and Francis (2003) report on trends within UK consumers towards more ethical goods generally and towards more 
responsible tourism products, specifically. Within the research community, Bramwell, Lane, McCabe, Mosedale, and Scarles, (2008, p. 253) suggest that there has been a resurgence of interest in:

"The idea that tourism- related actors can develop a sense of ethical and moral responsibility that has a resonance beyond selfinterest" and that there is at least some chance that "that this could change behaviours and contribute to more sustainable development."

Synonymous with this approach to tourism development are the associated principles of sustainable tourism, ethical tourism, ecotourism and alternative tourism and although Frey and George (2010) counsel us against using these terms interchangeably, they do state that each approach has the common goal of minimising negative impacts whilst maximising the positive effects. Sustainable tourism is future orientated, ethical tourism has a moral dimension, eco-tourism is primarily focussed on the environment and alternative tourism focusses on the individual's experience. Responsible tourism, on the other hand is about "managing the business in a way that benefits its local community, natural and business environment and itself” (Frey \& George, 2010, p. 622).

Much has been written on the benefits and potential of this approach to tourism with the introduction of publications such as Progress in Responsible Tourism attesting to the interest from within the research community. However this approaches does have its critics. Wheeller (1991; 2009) has long contended that responsible tourism is difficult to achieve in our contemporary culture of individualism and attempts at developing ecotourism and ethical tourism simply reflect self-interest rather than a sense of responsibility. Butcher's critique (2003; 2015) deplores the moralisation of leisure travel and suggests that an emphasis on 
responsibility within tourism is anti-development, individualistic and denigrates the ordinary traveller. Both are in agreement that these are worthy aspirations but are pessimistic as to whether they can be realised.

These critiques notwithstanding, the literature on self-guided trails suggests that the nature and potential of these tourism products is such that they could be usefully employed in the planning of more responsible tourism as defined above. These movements towards creating more beneficial trails may be small in scale but the literature and examples of good practice within the trails field suggest that they may be worth exploring further. This paper therefore goes on to review the literature on trails and routes within the context of the concept of responsibility in tourism and proposes key planning principles that can be derived from this review.

\section{Self-guided trails and routes}

\section{Definitions and development}

The self-guided trail is a means of organising the visitor experience by creating a pathway for walking, driving or other types of transportation that uses the natural and cultural heritage of the area through which it passes to create a themed, interpreted journey for visitor education and enjoyment (Silbergh, Fladmark, Henry, \& Young, 1994, p. 123). Trails range in scale from the site-specific to the international and can be followed on foot, by bicycle, on horseback, by car, by boat or even by diving along underwater trails 
(Alves, 2008). In this paper, this type of experience is described as a self-guided trail to differentiate it from a guided tour which may follow a similar route but where the interpretation is provided by a live tour guide

Although this paper is primarily concerned with the contemporary potential of the self-guided trail for responsible tourism development, the concept of the trail is as old as travel itself, having long helped to shape the patterns of human movement.

Travelling along a pre-determined route is fundamental to our sense of progress and the path is often used as a metaphor for life and self-discovery (Timothy \& Boyd, 2015). Early paths that marked the routes of ancient trade, migration and pilgrimage are still followed today with the traveller being taken through historic landscapes that provide a themed visitor experience. Despite their longevity these historic routes have only recently been rediscovered as tourism experiences. Similarly, the last three decades have seen the deliberate creation of new trails for recreation and touristic purposes. In many cases, these trails have been developed to promote access and recreation, to explore a conservation theme and to give a clear identity to places not already well-known by visitors (Hayes \& MacLeod, 2008). Where a new place-identity has been produced, trails development has been criticised for its selectivity, choosing attractive, visually appealing themes which may not always accurately represent local history, culture or interests (Urry \& Larsen, 2011; Skinner, 2015). As an experience that depends on the visual, trails can favour aspects of the toured environment that are spectacular, tangible and powerful although conversely, a trail can also be used as a means to challenge such 
approaches to the representation of culture, for example in exploring under-represented social groups and more transient expressions of culture (Shaw \& MacLeod, 2000; MacLeod, 2004; Frost, 2005; Taylor, 2015).

\section{Scale and purpose}

Self-guided trails vary significantly in terms of scale and purpose. At a local or site-specific level, trails can create new stories or themes for an established destination (e.g. Boston's Freedom Trail, US). At a regional level, sites can be linked by a trail for walking, cycling or driving (e.g. Mineral Tramways in Cornwall, UK). At a national level, different strands in a country's 'brand' can be articulated through a trail, for example Scotland's Whisky and Castles Trails and the Alsace Wine Route in France emphasise national identity through heritage and industry. International trails such as the Council of Europe's Cultural Routes cross borders and encourage networking to protect and promote European heritage and act as catalysts for social and economic development (Moulin \& Boniface, 2001; Council of Europe, 2011).

Trails are predominantly developed and funded by public sector agencies - local authorities, economic development agencies and tourist boards - and will also involve a range of stakeholders including individual sites and local communities (Hayes \&MacLeod 
2008). These wide-ranging stakeholders have diverse perspectives and careful collaboration is required for successful trail development and ongoing management (Timothy \& Boyd, 2015).

\section{Trails as responsible tourism products}

The self-guided trail has long been considered a useful interpretive and visitor management tool, routing visitors to specific sites and providing a meaningful visitor experience (Dartington Amenity Research Trust, 1978). Their value in directing people away from congested sites and providing a purposeful experience, perhaps far from established routes, has been recognised by those managing tourism in popular destinations. However, trails can also play a more significant role in the development of more responsible tourism. By nature they are flexible in their themes, have low start-up costs and require little infrastructural development. The Council of Europe has already recognised the role of sustainable cultural development in the creation of European Cultural Routes: the COE lists sustainable development as one of the priority areas when making decisions about certifying routes (Council of Europe, 2010). Weston and Mota (2012) comment on the need for more research focussing on trails development to address the pressure being placed on destinations to lower their carbon footprint - they consider self-guided trails to play a key role in this aim. 
The literature on self-guided trails seems to suggest that trails can be a facet of responsible tourism that improves the lives of host communities, creates business opportunities and enhances the visitor experience (Hayes \& MacLeod 2007; Rogerson, 2007; Oliveira et al., 2011; Marschall, 2012; Zabbini, 2012; Hayes \& MacLeod ). Self-guided trails therefore may contribute to more responsible tourism in the following ways: educating and entertaining the visitor in a purposeful manner; promoting alternative cultural themes/local cultural identity; promoting low-impact travel; spreading the economic benefits of tourism and encouraging business networks and clusters.

Using as a framework the three fields wherein responsible tourism is found in practice - social responsibility, economic responsibility and environmental responsibility (Goodwin, 2011) - this paper now goes on to review the potential of self-guided trails as responsible tourism products.

\section{Social responsibility}

Goodwin (2011) asserts that social responsibility in tourism is more than just endorsing the principle of sustainability stakeholders must accept responsibility for dealing with socio-cultural issues as they arise. These issues may include striving for social inclusion and addressing concerns with regards to authenticity and host-guest encounters. In reviewing the literature on self-guided trails, it is evident that they have the potential to contribute to more socially responsible tourism in the following areas. 


\section{Visitor experience}

Self-guided trails can be designed to allow visitors to explore both the beaten and unbeaten track and can include a number of official and less formal sites, thus helping the visitor towards a deeper understanding of the destination. A heritage trail developed around the historic core of the city of Saida in Lebanon was found to have increased visitors' cultural engagement with the district (Al-Hagla, 2010) compared with their experience of the destination without use of the trail. The host-guest encounters that were engineered as part of the trail design played an important role in this enhanced engagement with place.

\section{Alternative heritage themes/cultural identity}

Although theme-based heritage tourism has been deemed inauthentic (Urry \& Larsen, 2011), the dominant heritage theme of a destination can be challenged by a well-researched trail which maps out an alternative route for visitors seeking less well-worn stories. Shaw and MacLeod (2000) discuss the alternative history described in the Clerkenwell Trail in London's City Fringe which explores the vital role played by immigrant communities who serviced the City but often go unacknowledged. Similarly in Jamaica, Pattullo (1997, p. 144) describes plans to create an architectural heritage trail which will take visitors "from great house to railway station and vernacular cabin” in an attempt to present as balanced a view as possible. The culture of a minority is explored in Deyo et al. (2014) who examine trails in American Indian Country in the US, concluding that these routes allow the continuation of tribal practice and knowledge which has the dual benefit of enhancing visitor education and strengthening tribal identity. Markwell, Stevenson, and Rowe (2004) analyse attempts to address issues of gender, class and ethnicity through the development of a heritage trail in 
Newcastle, a city suburb in New South Wales, Australia. Although the development team were keen to include as many untold stories as possible in their trail interpretation, it is interesting to note that the outstanding landscape features which are key to creating a trail tended to emanate from dominant, male middle-class culture in that particular setting.

\section{Economic responsibility}

Goodwin (2011, pp.189-90) reminds us that:

"The central tenet of the Responsible Tourism movement is that all forms of tourism can be improved by taking responsibility for the economic impacts of tourism"

By their very nature, trails encourage the clustering of businesses and can therefore contribute to economic responsibility in their regions as explained below.

\section{Networks and community benefits}

Trails link sites and producers and thus form business clusters that should encourage interaction and community participation and this potential has recently been investigated by the Council of Europe in their report on the impact of European Cultural routes on 
SMEs (Council of Europe, 2011). The variety of stakeholders involved in developing trails necessitates good communication networks. If effective, these networks or clusters can lead to product development, joint marketing and the inclusion of local communities in the decision-making processes (Hardy, 2003; Meyer-Cech, 2005). In discussing European cultural routes, Moulin and Boniface (2001, pp. 233-4) underline the networking benefits to communities:

"Routes not only offer communities the opportunity of direct self-help but also allow each participating community along a route to benefit from being linked to the experience ... of other participants”.

The benefits of such co-operation is described by Telfer (2001) who outlines the strategic alliances formed between wineries, restaurants, hotels and tour operators on the Niagara Wine Route in Canada. Working together, these stakeholders have developed additional events along the route to extend the wine tourism season. Similarly, Briedenhann and Wickens (2004); Rogerson (2007); Meyer (2004) and Koscak, Colaric-Jakse, and Veljkovic (2014) discuss the potential of routes for promoting regional co-operation and economic development. Each are optimistic about the positive benefits that trails can bring but emphasise the need for strong planning and marketing approaches plus community involvement if these are to be realised (Marschall, 2012).

\section{Environmental responsibility}

The Cape Town Declaration reminds us that the environment should be managed throughout a destination's lifecycle and that environmental responsibility calls for the sustainable use of resources, for waste reduction, for awareness of a destination's carrying 
capacity and for “tourism to be used to promote environmental education and awareness amongst tourists” (cited in Goodwin, 2011, p. 213). The development of self-guided trails which are frequently experienced through walking, cycling or riding through a region is clearly an illustration of tourism that takes responsibility for the local environment. There are several examples of trails which have been developed along existing or under-used routes (such as rail trails effectively 'recycling' disused railway lines) that create new visitor experience without the need for infrastructural development. Other features relevant to environmental responsibility are outlined below.

\section{Transport and the environment}

The scale of the trail will determine the mode of transport used but it is possible to promote more environmentally responsible forms of transport on long distance trails as well as on shorter walking tours. The mode of transport can often be the key feature of the trail itself, for example in the case of long-distance walking and cycling routes and bridleways where the challenge of the trail is to complete it using traditional modes of transport. In these cases, it is important that the trail is adequately linked to public transportation to ensure that users can access the start and end points easily whilst leaving their cars behind (Davies, Lumsdon, \& Weston, 2012). The greater use of public transport can also be promoted through the trail interpretation, including information on services and connections.

Environmental education and visitor management 
The interpretation of the trail itself can be used to promote environmental awareness and conservation issues in situ. This has been found to both educate and enhance the experience of users (Hughes \& Morrison-Saunders, 2002; Oliveira et al., 2011). Additionally, trails can assist in visitor management strategies by suggesting that visitors explore less congested areas, thus improving the experience and lessening the environmental impacts on sensitive sites. The Greenwich Millennium Heritage Trails in London, UK encourage visitors to walk around the historic centre of Maritime Greenwich but they also extend the themes to less renowned neighbouring districts with a good supply of alternative attractions. Thus, Historic Woolwich and Tudor Eltham are interpreted through their own trails, encouraging both domestic and overseas users to 'explore hidden gems' and alleviate the pressures on the UNESCO heritage sites in Maritime Greenwich (Greenwich Tourism Partnership, 2000).

The preceding discussion suggests that, ideally, self-guided trails could play an important role in the development and management of more responsible urban and rural tourism but that strong partnerships, planning and evaluation is required to fully realise the potential benefits. Another key feature should be trail monitoring and evaluation -however, Leask and Barriere (2000, pp. 24-5) discovered in a survey of Scottish heritage trails that, "rather disappointingly, few of the heritage trails had carried out impact assessments prior to development”. Equally worryingly, over $60 \%$ of the sample did not carry out any monitoring of the trail after it was set up, so trail developers are unaware of visitor volume and the effectiveness of signage, interpretative materials and marketing strategies. Trail usage is difficult to monitor, particularly in remote regions or in busy urban centres where users cannot be readily 
differentiated from other visitors (Hayes \& MacLeod 2008). However, the positive economic impact of the Virginia Creeper Rail Trail in Virginia, US and the Path to Progress Trail in Pennsylvania, US, have both been measured using expenditure surveys of trail users and an analysis of existing site reports respectively (Strauss \& Lord, 2001; Bowker, Bergstrom, \& Gill, 2007) and the efficacy of signage and interpretation in a city heritage trail has been monitored in the case of the Old Saida Heritage Trail in Lebanon (Al-Hagla, 2010). New Global Positioning Systems (GPS) technology does make it easier to collect information on patterns of visitor movement and Hallo et al. (2012) report on its successful usage in nature-based trail environments.

In neglecting to evaluate impact and to monitor trails, developers may also be unaware of potential areas of conflict inherent in some trails, for example the "pilgrim-tourist dialectic" in the case of the Camino de Santiago where pious and secular motives may clash (Murray \& Graham, 1997). Severe problems can also arise in trails using sites that are culturally or politically sensitive as developers of the Ping Shan Heritage Trail in Hong Kong discovered. The local Tang clan who owned several of the historic sites on this prestigious trail effectively closed the trail when dissent arose over perceived mishandling of their ancestral heritage by the government (Cheung, 2003).

From the preceding discussion, it would therefore appear that a range of principles is required to inform the strategic planning and monitoring of trails that will contribute to more responsible tourism. Earlier analysis suggests that responsible tourism should enhance the lives of host communities, create better business opportunities and create enjoyable and meaningful tourist experiences. 
The principles proposed below which are derived from the literature and examples of good practice, embrace these concerns and suggest approaches to trail planning which will ensure that a responsible approach is built into the design and ongoing management of the trail.

\section{Principles for planning responsible trails}

\section{Planning socially responsible trails: The principle of effective site selection and consultation}

A self-guided trail is composed of a series of highlighted sites that explore a particular theme. The selection process should be informed by a series of clear criteria related to the trail's objectives. In planning for more responsible trails, these criteria will have an environmental and cultural dimension. Sites should be reasonably resilient to visitation, easily accessible and well managed. The chosen stops on the trail must also reflect the adopted theme, ideally represent authentic local culture and offer a range of ancillary services to visitors. The Blue Ridge Music Trail in the Southern Appalachian region of North Carolina and Virginia utilises a range of site selection criteria including geographic, hospitality and access, heritage and resource-based criteria (Blue Ridge National Heritage Area, 2015). These detailed criteria are designed to ensure that the main trail objective - that of promoting authentic, traditional community music events - is met. 
The Blue Ridge Trail site selection criteria include the important proviso that visitors are actually welcome at sites before they are included in the trail. Whilst this may seem an obvious point, the local community are often overlooked in the consultation process and this can affect the success of the trail (Leader-Elliott, 2005). Communities are important stakeholders in trail development and may be adversely affected by trail development, especially in circumstances where a trail promotes a theme that is inappropriate and unacceptable. In particular, where a trail provides easier access to inhabitants and cultural sites, local communities should be consulted (Timothy \& Boyd, 2015).

The Heritage Trails Uganda Project, managed by Action for Conservation Through Tourism (a UK NGO) and the Uganda Community Tourism Association provides a useful example of community consultation. The Trails were launched in 1999 as a means of providing more cultural attractions for visitors to Uganda and the Trails explore sites associated with the country's traditional kings, the Kabakas. Local communities whose villages and cultural sites were selected for inclusion in the Trails were consulted on their preferred levels of involvement and the types of visitor service they would like to develop, if any (Holland, Burian, \& Dixey, 2003). The results of the consultation showed that communities were generally happy to offer a range of services although there was slightly less enthusiasm for those services which offered visitors a greater 'backstage' access to their everyday lives (for example the provision 
of accommodation and meals). This type of survey could form the basis of ongoing trails monitoring with developers agreeing to reroute trails away from areas where local communities are experiencing the more negative effects of tourism development.

\section{Planning economically responsible trails: The principle of increased integration}

New trails should provide a unique experience and a proliferation of trails competing with existing offerings should be avoided. Ill-assorted trails will not necessarily be appreciated by visitors and will be difficult to market effectively. There is a need for an integrated approach to trail development and new products should be designed in tandem with existing trails to complement rather than compete with the tourism offer as Meyer-Cech (2005) and Horodnikova and Derco (2015) explain within the Austrian and Slovakian contexts respectively.

Trails link associated sites but it is also good practice to integrate the trail theme with relevant museum and gallery collections, referring visitors to local attractions and exhibitions where they might further their explorations. The trails offered by Culture 24 (a UK not-for-profit organisation promoting cultural education) are designed to bring together significant sites and artefacts in an attempt to highlight specific aspects of British culture, for example, Anglo-Sikh heritage (Culture24, 2015). These trails promote cultural tourism to lesser-known destinations and importantly, allow visitors to explore the geographic and social contexts of museum collections, thus enhancing understanding and appreciation. 
Trails should also be fully integrated with information sources for local services. This not only promotes local businesses but also provides a useful visitor service. Information on accommodation and catering is desirable for all trails and essential in the case of long-distance walking routes. Willard and Beeton (2012) report that the success of a trail depends as much on good service delivery en route, as it does to the trail experience itself. Local information can be themed to complement the trail, for example Scotland's Castle Trail playfully includes a selection of castle accommodation for the visitor who wants to extend the fantasy of castle-living after a day of viewing Scotland's sites. A responsible trail should therefore make sensitive use of local culture and businesses by bringing together the tourist and local communities along the route to the benefit of both (Al-Hagla, 2010).

\section{Planning environmentally responsible trails: The principle of responsible interpretation and information}

The media used to interpret the trail offers an opportunity to present a responsible message to users. Interpretative panels and printed guides can educate users about appropriate behaviour - what Weaver describes as "proper trail etiquette” (1995: 602) - and the consequences of irresponsible actions. Information about conservation activity and projects may also be conveyed through trail interpretation and this can enhance the visitor experience (Hughes \& Morrison-Saunders, 2002; Oliveria et al., 2011). Good practice would also include using materials from a natural, sustainable resource (preferably local) to make the signage, panels and printed

materials. In urban environments, signage should be discreet and preferably placed on existing structures. Use should be made of low 
impact technological solutions such as mobile applications and audio downloads which can be used flexibly in the field, utilising the user's own mobile phone, tablet, MP3 player or iPod. These interpretive formats are sustainable and enhance the visitor experience providing a more sensory and tailored engagement with the setting. (Butler, 2007; Kounavis, Kasimati, \& Zamani, 2012).

Although all newly developed trails should consider using walking, cycling or riding as the main focus, enabling trail users to access public transport is vital and the siting of new trails should be integrated with the existing public transportation infrastructure. The network of UK National Trails provides detailed information on public transport access at various starting points along the routes. Some of the trails are even connected into continental European public transport networks, for example the Cleveland Trail (National Trails, 2015).

\section{The principle of impact analysis and monitoring}

An overarching planning principle is that of impact analysis and monitoring. Developers of responsible trails need to understand the environmental, socio-cultural and economic impacts of trail users on the trail environment (Timothy \& Boyd, 2015). It is also necessary to evaluate the visitor experience and trail usage in the field. Consequently, in planning new trails, developers should integrate appropriate mechanisms to measure and analyse user impacts. Defining a carrying capacity and deciding on appropriate indicators - environmental, socio-cultural, psychological and managerial - and how these indicators might be measured is a method 
utilised in heritage management (Hall and McArthur 1998: 125) and could usefully be applied to the trail. Leask and Barriere describe the practice of counting the number of cars, people and cyclists using paths and sites and photographic and observation techniques in measuring the environmental impacts of users on The Trossachs Trail in central Scotland (Leask \& Barriere, 2000, pp.121-122). Appropriate socio-cultural indicators might include systematic consultation with the host community to ensure that their needs are being met.

In particularly sensitive environments, a self-policing scheme where trail users register their itineraries with the local tourism organisation may be appropriate. This idea was suggested as part of the plans for the Montserrat Heritage Trail network, with the intention that trail usage could be monitored and numbers restricted or users re-scheduled as necessary (Weaver, 1995). Maxwell (2012) reports on the monitoring required in the over-used Inca Trail in Peru and contends that more effort is now spent on policing visitors than conserving the environment.

A certification or passport scheme would also enable trail developers to monitor trail usage and attendance at key sites. Walkers or cyclists on the Camino de Santiago can collect dated stamps from churches, inns and cafes along the pilgrim route allowing them to prove that they have undertaken a section of the journey. This proof then qualifies them for a Compostela - a document issued by the Santiago cathedral authorities (Murray \& Graham, 1997, p. 519). Whilst it may be regretted that “pilgrims” 
qualify for this document “on the grounds of physical achievement rather than any necessarily spiritual motivation,” the practice has benefits in assisting in the monitoring of trail usage and contributing to visitor satisfaction and sense of achievement.

It is also essential to understand the visitors' experience of the trail to ascertain whether trail objectives are being met and to make modifications although, as discussed earlier, this is infrequently carried out. However, this knowledge could be gained through conducting visitor surveys on the trail itself and at associated sites to monitor usage, modes of transport used, visitor spend and levels of motivation and satisfaction. In particular where a trail is formed of a collection of sites, it is useful to know the marketing impact of the trail concept itself. Are visitors simply visiting the site in isolation or are they following the trail in sections or in its entirety? An economic impact study of the Path of Progress trail in South Western Pennsylvania uncovered some interesting data on attendance patterns and non-resident visitor spend at the 13 sites on the Path (Strauss \& Lord, 2001). It was found that overall visitor attendance at sites did not significantly increase with the launching of the trail in 1988 but the proportion of non-residents amongst the visitors did increase and with them a rise in economic activity within the region. The Path had not significantly increased the number of visitors to sites but was enhancing their overall attractiveness to non-residents, thus boosting the local economy. However it is interesting to note that the evaluation of users is not always affordable for trail developers as Markwell et al. (2004) note. Finally, it is important to build in a strategy for the ongoing management and evaluation of a trail to ensure its future. Despite the good practice evidenced in 
Uganda’s Kabaka Heritage Trails discussed above, more recently, local communities feel that the trail had been left to flounder with no future management strategy in place when the associated NGO returned to the UK (Ahebwa, Aporu, \& Nyakaana, 2015).

The trail planning principles proposed above offer guidance for trail developers seeking to utilise these popular tourism products to promote responsible tourism in their destinations. Using these planning principles, a developer would be assisted in the key stages of producing a responsible self-guided trail which are: setting trail objectives, creating a partnership of stakeholders, the creation of an appealing and relevant theme that reflects local identity; establishing site selection criteria and choosing sites that are appropriate to the theme and that will enhance the local economy; choosing an environmentally responsible interpretation format and setting up systems for evaluation and monitoring which should include input from local stakeholders.

This paper now ends with a case study of recent trail development in Cornwall, UK which clearly demonstrates a responsible approach to new product development and shows what a responsibly-planned trail looks like 'on the ground.' In this example, a set of inter-linked trails was developed out of the existing infrastructure to enhance the local tourism product, support the regional economy, interpret an important local heritage theme and provide safe and sustainable travel routes for residents. 


\section{Mineral Tramways, Cornwall, UK}

Cornwall is the most south westerly region of the United Kingdom and is an area characterised by an extensive coastline, small towns and villages and open moorland. Cornwall is recognized as a Celtic nation and local cultural identity is strong, with the Cornish language spoken by a minority of local people. Historically, along with fishing, tin and copper mining were important industries but these activities went into decline in the late 1900s. The advent of the railways brought visitors, tourism grew in the $20^{\text {th }}$ century and the region is still a very popular domestic tourism destination. However it is one of the poorest parts of the UK in terms of per capita GDP and average household incomes. It is within this context that Cornwall’s Mineral Tramways project was developed (Cornish Mining World Heritage, n.d.; UNESCO, 2014).

The Mineral Tramways is a network of interlinked walking, cycling and horse-riding trails set within the landscape of Cornwall’s central mining district. The trails are predominantly off-road and there is in excess of $60 \mathrm{~km}$ of routes to be followed. The Mineral Tramways Heritage Project began in 2005 with the purpose of adding new routes to existing trails in order to open up access to the many mining heritage attractions and historic mining villages within the area. The existing trails (The Coast to Coast Trail, The Great Flat Lode Trail and The Tresavean Trail) each reflect mining themes and routes, and these have now been augmented by a further 4 new trails (Cornwall Council . 
The majority of the trails follow the original tramways and railway routes which were used to transport ore and supplies to and from the area's tin and copper mines to the Cornish ports. They take in historic villages and mining heritage sites and integrated signage and interpretation has been provided. The Mineral Tramway Trails are fully linked into other existing paths, public transport routes and local businesses. The intention is to provide safe walking and cycling areas for recreation and for local communities travelling to school and work in addition to an enhanced experience for visitors (Cornwall Council, 2014).

The Project was a $£ 6$ million regeneration project funded by Objective One, the EU funding programme set up to reduce the differences in social and economic conditions across the Union. This funding was awarded to areas with prosperity at $75 \%$ or less than that of the European average. Funds awarded must be matched locally so the remainder of the sum came from the South West Regional Development Agency, The Heritage Lottery Fund and the various Parish and Town councils within the area. The exposure that the project lent to the area contributed to its success in being designated a UNESCO World Heritage Site in 2006. Thus the Mineral Tramways are now part of the Cornwall and West Devon Mining Landscape World Heritage Site (WHS). The Site is subject to ongoing monitoring and although specific data on visitor numbers on the Tramway trails themselves are not yet available, visitor numbers across the entire site have been reported as remaining static over the last 4 years with a minor increase in the present year. However, the Periodic Report for the WHS for 2014 reports that the trails and routes in the site have contributed to the value of the offering by providing “excellent education, information and awareness building” (Cornish Mining World Heritage, 2014a, p.8). 


\section{Key Features}

The case study above illustrates the potential for developing trails that contribute to more responsible tourism as follows:

1. The trail explores a theme that's appropriate to the region - mining heritage is a key strand in Cornwall's history and is a source of pride for local community (Coupland \& Coupland, 2014).

2. Social and cultural identity is enhanced and celebrated - tin and copper mining created an international identity for Cornwall and the roots of this are celebrated through the WHS. More recently, the promotion of Cornish locations of a popular TV series Poldark (which includes strong mining themes) pushed up visitation to sites by 90\% over Easter 2015 (Cornish Mining World Heritage, 2015). Festivals and events are held at key sites including a specially commissioned play entitled Tins and Fishes

3. Local communities are involved in decision making via WHS management - and contribute through volunteering projects such as Helping Hands for Heritage project (Cornish Mining World Heritage, 2015).

4. Education is a key feature - including the promotion of school visits, a dedicated children's activity pack and events integrated with the trail network

5. Increased visitor numbers and expenditure in region - the trail contributes to the enhanced awareness of the region and overall increase in visitor numbers. 
6. Increased integration and consolidation of the heritage offering - the trail is fully integrated with existing trails (e.g. National Cycle network and Cornish Trails) and brings together a number of disparate heritage and cultural elements and packages them effectively.

7. Trails provide links to local businesses - visitor attractions, historic villages, Tourist Information Centres, pubs, hotels, cafes etc. are integrated.

8. Uses existing routes/infrastructure - no new structural development was required.

9. Encourages use of public transport - travel information is incorporated into all trails literature and website.

10. Sustainability message is incorporated in all information and interpretation - low-impact, audio versions of the trails (where a spoken rather than textual guide is provided to interpret the route) are available to download free from the website.

11. Provides safe, low impact routes for visitor and resident use - much of the trail network is traffic free and links villages and attractions thus providing safe routes for local residents to utilise. The sites on the trails are encouraged to adopt sustainable practice and are rewarded with certification and awards through the WHS Heritage Champions programme (Cornish Mining World Heritage, 2014b). 


\section{Conclusion}

Trails have been used to good effect in place-marketing as they can create identities and increase the tourism potential of lessfrequented destinations. However in sensitively addressing the issues of site selection, consultation, integration, monitoring and interpretation, it can be seen that trail developers can also create tourism products that are socially, economically and environmentally responsible. As the example of the Mineral Tramways above illustrates, well-planned trails can enhance the visitor experience, creating a purposeful and satisfying interpretation of a destination. They can increase visitor spend and promote the usage of local services, and they can help to build strong networks to improve the business performance of a region, thus becoming popular resources that are embraced by both locals and visitors alike. Their flexibility allows them to explore alternative histories and cultures and, if designed to be fully integrated with public transport providers, they can promote tourism which is less damaging to both natural and built environments. Carefully designed trails literature can convey an environmentally responsible message and mobile applications may be utilised to provide low-impact interpretation. Trails can therefore play an important role in the development of more responsible tourism and would certainly repay more serious attention from the tourism research community. In particular, more detailed case studies of successful trails would be a useful contribution to the literature as would a more sustained effort to evaluate the activities and experiences of trail users and the impacts of their visits. 


\section{References}

Ahebwa W.M., Aporu, J.P. \& Nyakaana, J.B. (2015). Bridging community livelihoods and cultural conservation through tourism: Case study of Kabaka heritage trail in Uganda. Tourism and Hospitality Research, 11, 1-13. doi:10.1177/1467358415589659

Al-Hagla, K.S. (2010). Sustainable urban development in historical areas using the tourist trail approach: a case study of the cultural heritage and urban development (CHUD) project in Saida, Lebanon. Cities, 27, 234-248. doi:10.1016/j.cities.2010.02.001

Alves, F. J.S. (2008). Underwater archaeological trails. Museum International, 60, 81-90. doi:10.1111/j.1468-0033.2008.00668.x

Blue Ridge National Heritage Area (2015) Blue Ridge music trails of North Carolina: Submit an event. Retrieved from http://www.blueridgemusicnc.com/find-music/submit-an-event

Bowker, J.M., Bergstrom, J.C., \& Gill, J. (2007). Estimating the economic value and impacts of recreational trails: A case study of the Virginia Creeper rail trail. Tourism Economics, 13, 241-260. doi:10.5367/000000007780823203

Bramwell, B., Lane, B., McCabe, S., Mosedale, J., \& Scarles, C. (2008). Research perspectives on responsible tourism. Journal of Sustainable Tourism, 16, 253-257. doi:10.1080/09669580802208201 
Briedenhann, J., \& Wickens, E. (2004). Tourism routes as a tool for the economic development of rural areas -vibrant hope or impossible dream? Tourism Management, 25, 71-79. doi:10.1016/S0261-5177(03)00063-3

Butcher, J. (2003). The moralisation of tourism: sun, sand... and saving the world. London: Routledge. Butcher, J. (2015). Ethical tourism and development: The personal and the political. Tourism Recreation Research, 40, 71-80.

doi:10.1080/02508281.2015.1010360

Butler, T. (2007). Memoryscape: How audio walks can deepen our sense of place by integrating art, oral history and cultural geography. Geography Compass, 1(3), 360-372. doi:10.1111/j.1749-8198.2007.00017.x

Cheung, S.C.H. (2003). Remembering through space: The politics of heritage in Hong Kong. International Journal of Heritage Studies, 9, 7-26. doi:10.1080/1352725022000056604

Cornish Mining World Heritage (n.d.). Cornwall and West Devon Mining Landscape World Heritage Site Management Plan 20132018. Retrieved from http://www.cornish-mining.org.uk/world-heritage-site-status\#What is a WHS?

Cornish Mining World Heritage (2014a). Periodic Report- Second Cycle. Retrieved from http://whc.unesco.org/en/list/1215/documents/

Cornish Mining World Heritage (2014b). Discover the Extraordinary: Project Evaluation Summary Retrieved from https://www.cornish-mining.org.uk/sites/default/files/WHS\%20DTE\%20Project\%20Evaluation\%20Summary.pdf

Cornish Mining World Heritage (2015). Cornish Mining: Newsletter of the Cornwall and West Devon Mining Landscape World Heritage Site. Retrieved from https://www.cornish-mining.org.uk/sites/default/files/Cornish_Mining_summer_2015.pdf

Cornwall Council (2014). The Mineral Tramways. Retrieved from http://www.cornwall.gov.uk/environment-andplanning/countryside/cycle-routes-and-trails/the-mineral-tramways/

Council of Europe (2010). Cultural Routes of the Council of Europe: Operational Framework. Retrieved from http://www.coe.int/t/dg4/cultureheritage/culture/routes/default_en.asp 
Council of Europe (2011). Impact of European Cultural Routes on SMEs' innovation and competitiveness (provisional edition). Retrieved from https://www.coe.int///dg4/cultureheritage/culture/routes/StudyCR_en.pdf

Coupland, B., \& Coupland, N. (2014). The authenticating discourses of mining heritage tourism in Cornwall and Wales. Journal of Sociolinguistics, 18, 495-517. doi:10.1111/josl.12081

CULTURE24. (2015). Arts and Crafts Trail. Retrieved from http://www.culture24.org.uk/places-to-go/westmidlands/birmingham/tra24334

Dartington Amenity Research Trust (1978). Self-guided trails: An appraisal of 46 self-guided trails. Cheltenham: Countryside Commission.

Davies, N. J., Lumsdon, L.M., \& Weston, R. (2012). Developing recreational trails: Motivations for recreational walking. Tourism Planning and Development, 9, 77-88. doi:10.1080/21568316.2012.653480

Deyo N., Bohdan, M., Burke, R., Kelley, A., Van Der Werff, B., Blackmer, E.D...Reo, N.J. (2014). Trails on tribal lands in the United States. Landscape and Urban Planning, 125, 130-139. doi:10.1016/S0969-6989(00)00023-0

Frey, N., \& George, R. (2010). Responsible tourism management: The missing link between business owners' attitudes and behaviour in the Cape Town tourism industry. Tourism Management, 31, 621-628. doi:10.1016/j.tourman.2009.06.017

Frost, W. (2005). Making an edgier interpretation of the gold rushes: Contrasting perspectives from Australia and New Zealand. International Journal of Heritage Studies, 11, 235-250. doi:10.1080/13527250500160526

Goodwin, H. (2011). Taking Responsibility for Tourism. Oxford: Goodfellow Publishers.

Goodwin, H., \& Francis, J. (2003). Ethical and responsible tourism: Consumer trends in the UK. Journal of Vacation Marketing, 9, 271-284. doi:10.1177/135676670300900306

Greenwich Tourism Partnership (2000). Greenwich Millennium Heritage Trails - Trail Guide. 
Hall, C. M., \& Mcarthur, S. (1998). Integrated heritage management: Principles and practice. London: The Stationery Office.

Hallo, J.C., Beeco. J.A., Goetcheus, C., McGee, C.J., McGehee, N.G. \& Norman, W.C. (2012). GPS as a method for assessing spatial and temporal use distributions of nature-based tourists. Journal of Travel Research, 51, 591-606. doi:10.1177/0047287511431325

Hardy, A. (2003). An investigation into the key factors necessary for the development of iconic touring routes. Journal of Vacation Marketing, 9, 314-330. doi:10.1177/135676670300900402

Hayes, D., \& MacLeod, N. (2007). Packaging places: Designing heritage trails using an experience economy perspective to maximise visitor engagement. Journal of Vacation Marketing, 13 (1), 45-58. doi: 10.1177/1356766706071205

Hayes, D., \& MacLeod, N. (2008). Putting down routes: An examination of local government cultural policy shaping the development of heritage trails. Managing Leisure, 13 (2), 57-73. doi: 10.1080/13606710801933420

Holland, J., Burian, M., \& Dixey, L. (2003). Tourism in poor rural areas: Diversifying the product and exploring the benefits in rural Uganda and the Czech Republic (Pro-Poor Tourism Working Paper Series No. 12). Retrieved from

http://Www.Propoortourism.Info/Library.Html

Horodnikova, J., \& Derco, J. (2015). Dark tourism, thematic routes and possibilities for innovation in the Slovak Republic. Tourism, 63(2), 241-246. Retrieved from http://hrcak.srce.hr/139580

Hughes, M., \& Morrison-Saunders, A. (2002). Impact of trail-side interpretive signs on visitor knowledge. Journal of Ecotourism, 1, 122-132. doi:10.1080/14724040208668119

Koscak, M., Colaric-Jakse, L., \& Veljkovic, B. (2014). The quest for excellence and a socially responsible approach to the planning process for sustainable tourism development: A case study of Slovenia. Tourism, 62, 189-200. Retrieved from http://hrcak.srce.hr/index.php?show=clanak\&id_clanak_jezik=185474\&lang=en

Kounavis, C.D. Kasimati, A. E., \& Zamani, E.D. (2012). Enhancing the tourism experience through mobile augmented reality: challenges and prospects. International Journal of Engineering Business Management, 4, 1-6. doi:10.5772/51644 
Leader-Elliott, L. (2005). Community heritage interpretation games: A case study from Angaston, South Australia. International Journal of Heritage Studies, 11, 61-171. doi:10.1080/13527250500070493

Leask, A., \& Barriere, O. (2000). The development of heritage trails in Scotland. Insights, January, 117-123.

MacLeod, N. (2004). Seeing places: A critique of the heritage trail as a visual interpretation of place. In C. Aitchison \& H. Pussard (Eds.), Leisure, space and visual culture: Practices and meanings (pp. 61-77). Eastbourne: Leisure Studies Association.

MacLeod, N., \& Hayes, D. (2013). Understanding self-guided trails: Two explorative typologies. Managing Leisure, 18(4), $257-272$. doi: 10.1080/13606719.2013.809182

Markwell, K., Stevenson, D., \& Rowe, D. (2004). Footsteps and memories: Interpreting an Australian urban landscape through thematic walking tours. International Journal of Heritage Studies, 10, 457-473. doi:10.1080/1352725042000299063

Marschall, S. (2012). Sustainable heritage tourism: The Inanda Heritage Route and the 2010 FIFA World Cup. Journal of Sustainable Tourism, 20, 721-736. doi:10.1080/09669582.2011.638385

Maxwell, K. (2012). Tourism, environment and development on the Inca Trail. Hispanic American Historical Review, 92, $143-171$. doi:10.1215/00182168-1470995

Meyer, D. (2004). Tourism routes and gateways: Key issues for the development of tourism routes and gateways and their potential for pro-poor tourism (Tourism Working Papers). Retrieved from http://195.130.87.21:8080/dspace/handle/123456789/519

Meyer-Cech, K. (2005). Regional cooperation in rural theme trails. In D. Hall, I. Kirkpatrick, \& M. Mitchell (Eds.), Rural tourism and sustainable business (pp. 137-148). Clevedon: Channel View.

Moulin, C., \& Boniface, P. (2001). Routeing heritage for tourism: Making heritage and cultural tourism networks for socio-cultural development. International Journal of Heritage Studies, 7, 237-248. doi:10.1080/13527250120079411

Murray, M., \& Graham, B. (1997). Exploring the dialectics of route-based tourism: The Camino De Santiago. Tourism Management, 18. 513-524. doi:10.1016/S0261-5177(97)00075-7 
National Trails (2015). National Trails. Retrieved from http://www.nationaltrail.co.uk/

Oliveira, M.R., Pita, C., Goncalves, J.M.S., Leite, L., Costa, C., \& Erzini, K. (2011). Ecotourism snorkelling routes at Marinha Beach. Journal of Coastal Research, 61, 274-281. doi:10.2112/SI61-001.26

Patullo, P. (1997). Reclaiming the heritage trail: Culture and identity. In L. France (Ed.), The Earthscan reader in sustainable tourism. (pp. 135-147). London: Earthscan Publications

Prideaux, B., \& Carson, D. (2003). A framework for increasing understanding of self-drive tourism markets. Journal of Vacation Marketing, 9, 307-313. doi:

Responsible Tourism Partnership (2002) Cape Town Declaration. Retrieved from http://Www.Responsibletourismpartnership.Org/Capetown.Html

Rogerson, C. M. (2007). Tourism routes as vehicles for local economic development in South Africa: The example of the Magaliesberg Meander. Urban Forum, 18, 49-68. doi:10.1007/s12132-007-9006-5

Shaw, S. J. And MacLeod, N. (2000). Creativity and conflict: Cultural tourism in London's City Fringe. Tourism, Culture and Communication, 2, 165-175. Retrieved from

https://www.cognizantcommunication.com/cccSiteFiles/Tourism_Culture/tcc23abs.html\#tcc23abs2

Silbergh, D., Fladmark, M., Henry, G., \& Young, M. (1994). A strategy for theme trails. In J.M. Fladmark (Ed.), Cultural Tourism (pp. 123-146). London: Donhead.

Skinner, J. (2015). Walking the Falls: Dark tourism and the significance of movement on the political tour of West Belfast. Tourist Studies, 10, 1-17. doi:10.1177/1468797615588427

Spenceley, A. (2008). Responsible tourism: Critical issues for conservation and development. London: Earthscan.

Strauss, C. H. And Lord, B.E. (2001). Economic impacts of a heritage tourism system. Journal of Retailing and Consumer Services, 8, 199-204. doi:10.1016/S0969-6989(00)00023-0 
Taylor, E.P. (2015). Alternate routes: Interpretive trails, resistance and the view from East Jerusalem. Journal of Community Archaeology and Heritage, 2(2), 106-120. doi:10.1179/2051819615Z.00000000032

Telfer, D. J. (2001). Strategic alliances along the Niagara Wine Route.Tourism Management, 22, 21-30. doi:10.1016/S02615177(00)00033-9

Timothy, D. J., \& Boyd, S.W. (2015). Tourism and trails: Cultural, ecological and management issues. Bristol: Channel View.

UNESCO. (2014). Cornwall and West Devon Mining Landscape.

Retrieved from http://whc.unesco.org/en/list/1215/

Urry, J., \& Larsen, J. (2011). The tourist gaze ( $3^{\text {rd }}$ Ed). London: Sage.

Weaver, D.B. (1995). Alternative tourism in Montserrat. Tourism Management, 16, 593-604. doi:10.1016/0261-5177(95)00082-8

Weston, R., \& Mota, J.C. (2012). Low carbon tourism travel: Cycling, walking and trails. Tourism Planning and Development, 9, 1-3. doi:0.1080/21568316.2012.658168

Wheeller, B. (1991). Tourism's troubled times: responsible tourism is not the answer. Tourism Management, 12(2), 91-96. doi:10.1016/0261-5177(91)90062-X

Wheeller, B. (2009). Heritage tourists: Responsible (f)or what? Tourism Recreation Research, 34, 84-87. doi:10.1080/02508281.2009.11081578

Willard, P., \& Beeton, S. (2012). Low impact experiences: Developing successful rail trail tourism. Tourism Planning and Development, 9, 5-13. doi:10.1080/21568316.2012.653476

Zabbini, E. (2012). Cultural routes and intangible heritage. Alma Tourism, 5, 59-80. doi:10.6092/issn.2036-5195/3188 